\title{
The effect of a synthetic double layer hydroxide on the rate of $\mathrm{II} \rightarrow \mathrm{I}$ phase transformation of poly(1-butene)
}

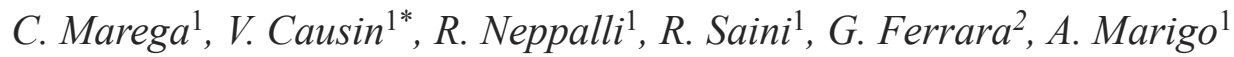 \\ ${ }^{1}$ Dipartimento di Scienze Chimiche, Università di Padova, and INSTM Research Unit, via Marzolo 1, 35131 Padova, Italy \\ ${ }^{2}$ LyondellBasell Poliolefine Italia SpA - Centro Ricerche 'Giulio Natta', P.le Donegani 12, 44100 Ferrara, Italy
}

Received 14 April 2011; accepted in revised form 16 June 2011

\begin{abstract}
Perkalite is an unusual clay in the domain of polymer-based nanocomposites. In this paper, the use of perkalite as a filler for poly(1-butene) was investigated. Particular attention was posed on the study of the effect of this particular kind of clay on the rate of II $\rightarrow$ I phase transition of the matrix. Wide angle X-ray diffraction (WAXD), small angle X-ray scattering (SAXS), transmission electron microscopy (TEM) and differential scanning calorimetry (DSC) were used to determine the structure and morphology of the samples, the degree of dispersion of the filler and to follow the kinetics of the phase transition of poly(1-butene). Mechanical properties were moreover measured. Perkalite was found to increase the rate of $\mathrm{II} \rightarrow \mathrm{I}$ phase transition with respect to the neat matrix, because it affected the free energy of the crystalline phase, by decreasing the perfection of the crystals. Rather than the disruption of the regular ordering at a crystalline cell level, the effect on the lamellar morphology seems to be preponderant. The fragility of perkalite layers and the substantial reduction of the tactoids did not allow to influence the entropic factor to the phase diagram of poly(1-butene), because the filler was not able to locally increase the pressure on the nascent crystalline domains. Perkalite was therefore not able to achieve a direct formation of the phase I of poly(1-butene) directly from the melt.

The reduction of the size of perkalite tactoids confirmed that poly(1-butene) is very efficient in homogeneously dispersing the filler, thereby justifying the use of the materials produced in the present study as viable masterbatches for the production of polyolefin-based nanocomposites.
\end{abstract}

Keywords: nanocomposites, poly(1-butene), perkalite

\section{Introduction}

Ever since its discovery in 1954, isotactic poly(1butene) (PB) was recognized for its remarkable properties. PB has superior toughness, tear strength, flexibility and creep with respect to other polyolefins, and it also displays a better resistance to stress cracking, to impact, to abrasion and to high temperature. An important drawback affecting the direct commercial exploitation of this polymer is related to the complex relationship between the kinetics and thermodynamics of its polymorphism. When PB is crystallized from the melt, it preferentially crystallizes according to the tetragonal phase II, which on the other hand is metastable at room temperature, and it spontaneously converts to the hexagonal phase I, with a concurrent loss of dimensional stability of molded items. This transition requires several days to be completed $[1,2]$. The thermodynamically favored phase I has moreover improved physical-mechanical properties with respect to phase II $[1,3,4]$, so acceleration of the II $\rightarrow$ I phase transition is key for the commercial development of PB. In previous works, it was shown that addition of montmorillonite clay could be exploited to increase the rate of this transition [3-7]. Coupling the role of clay with the effect of the insertion of ethylene

\footnotetext{
${ }^{*}$ Corresponding author, e-mail: valerio.causin@unipd.it

(c) BME-PT
} 
comonomeric units in the PB chains, crystallization from the melt directly into phase I was reported for the first time [7].

Layered silicates have been traditionally chosen as nanofillers due to their wide availability and relatively low cost. Most of the research in this field has been centered on smectite-type materials, such as montmorillonite or hectorite, which are commonly found in nature, but they can not be easily synthesized. On the contrary, layered double hydroxides (LDH) have been much less employed as nanofillers. The formula of $\mathrm{LDH}$ can be generalized as $\left|\mathrm{M}_{\mathrm{x}}^{2+} \mathrm{M}_{1-\mathrm{x}}^{3+}(\mathrm{OH})_{2}\right|_{\text {intral }}\left|A_{\mathrm{x} / \mathrm{m}}^{\mathrm{m}-} \cdot n \mathrm{H}_{2} \mathrm{O}\right|_{\text {inter, }}$, where $\mathrm{M}^{2+}$ and $\mathrm{M}^{3+}$ are metal cations, $A$ are the anions and intra and inter designate the intralayer domain and the interlayer space, respectively. The structure of LDH derives from brucite, i.e. $\operatorname{Mg}(\mathrm{OH})_{2}$, with layers obtained by isomorphous substitution of divalent cations. The replacement of $\mathrm{Mg}^{2+}$ by $\mathrm{M}^{3+}$ ions generates a net positive charge that is balanced by incorporation of anions in interlayer space. Differently from smectite-type clays, LDH are much more prone to be synthesized. LDH have high charge density and a high content of interlayer anions and water molecules, resulting in strong electrostatic interactions between the sheets and strong hydrophilic properties. As a consequence, LDH layers are very tightly stacked and are quite difficult to exfoliate [8-12].

Never LDHs were applied for the preparation of PB-based nanocomposites, although these fillers showed a big potential. Perkalite is especially interesting due to the advantage of being compliant with the European Union regulations for materials coming into contact with foodstuffs [12].

In the cited work on PB-based nanocomposites, an interesting affinity of PB with clay emerged. Differently from what normally happens with polypropylene or polyethylene, a rather extensive reduction of clay tactoid size could be achieved in PB [4-7]. This feature and the compatibility of $\mathrm{PB}$ with polypropylene open a potential for PB as a highly performing vector to include clay within a polypropylene matrix. The classical approach to pursue this objective is the use of maleated polypropylene as a compatibilizer [13]. Despite the big amount of research carried out on this subject, the recent literature shows just very marginal improvements with respect to previous results [14]: a change in per- spective is necessary in the preparation techniques of these materials. The use of masterbatches based on a highly performing material such as PB to introduce clay into an otherwise recalcitrant matrix such as polypropylene can be an example of such novel approach.

In this work, the preparation and the characterization of a series of clay-PB nanocomposites are reported. Such materials will be used as masterbatches to be subsequently included into polypropylene matrices [15].

In this paper, focus will be posed on the characteristics and properties of the materials, in order to evaluate their physical mechanical performance and also to investigate the effect of clay on the rate of $\mathrm{II} \rightarrow \mathrm{I}$ phase transition.

The structure, morphology and phase transition of the materials were studied by wide-angle X-ray diffraction (WAXD), small-angle X-ray scattering (SAXS), differential scanning calorimetry (DSC) and transmission electron microscopy (TEM).

\section{Experimental}

\subsection{Materials and sample preparation}

The samples were prepared using PB0300M, a commercial isotactic poly(1-butene) produced by LyondellBasell Polyolefins (Ferrara, Italy) $\left(\bar{M}_{\mathrm{w}}=\right.$ $284196 \mathrm{~g} / \mathrm{mol}, \bar{M}_{\mathrm{w}} / \bar{M}_{\mathrm{n}}=3.6$, density $\left.=0.915 \mathrm{~g} / \mathrm{cm}^{3}\right)$. The melt flow rate of this matrix was $4 \mathrm{~g} / 10 \mathrm{~min}$ $\left(190^{\circ} \mathrm{C}, 2.16 \mathrm{~kg}\right.$ according to ASTM D-1238) and $70 \mathrm{~g} / 10 \mathrm{~min}\left(190^{\circ} \mathrm{C}, 10 \mathrm{~kg}\right.$ according to ASTM D1238).

As compatibilizer, Polybond 3200 (Chemtura, Middlebury, CT, USA), a maleated PP $(\mathrm{MFR}=$ $115 \mathrm{~g} / 10 \mathrm{~min}$ ASTM D- 1238 at $190^{\circ} \mathrm{C}$ and $2.16 \mathrm{~kg}$, $1 \% \mathrm{w} / \mathrm{w}$ maleic anhydride, density $=0.91 \mathrm{~g} / \mathrm{cm}^{3}$ ) was used. Perkalite is a synthetic hydrotalcite clay, treated with anionic surfactants (Akzo Nobel Polymer Chemicals, Deventer, The Netherlands). In particular the Perkalite F100 grade was employed, where the anion surfactants are hydrogenated fatty acids.

The components were mixed in a reciprocating single screw extruder, Buss MDK 70 (Pratteln, Switzerland). The extrusion average temperature was $180^{\circ} \mathrm{C}$, the residence time was $80 \mathrm{~s}$. The profile of the employed screw was obtained by that normally used with talc by the elimination of restriction rings to optimize distributive mixing and residence time 
Table 1. Formulation of the studied samples

\begin{tabular}{|l|c|c|c|}
\hline \multicolumn{1}{|c|}{ Sample } & PB [\%] & Compatibilizer [\%] & Perkalite [\%] \\
\hline PB0 & 100 & 0 & 0 \\
\hline PB5 & 90 & 5 & 5 \\
\hline PB10 & 80 & 10 & 10 \\
\hline PB15 & 70 & 15 & 15 \\
\hline PB20 & 60 & 20 & 20 \\
\hline PB5NoC & 95 & 0 & 5 \\
\hline PB10NoC & 90 & 0 & 10 \\
\hline
\end{tabular}

[13]. Table 1 summarizes the formulation of the samples employed. To rule out the effect of processing, also the matrix polymer alone was subjected to extrusion at the same conditions of the composites. For the subsequent WAXD, SAXS, DSC and PLOM analyses and for the study of the II $\rightarrow$ I transition, test specimens were prepared from both the matrix and the composites by melting aliquots of the samples between two aluminum plates in a press at $170^{\circ} \mathrm{C}$ for $10 \mathrm{~min}$, in order to cancel any previous thermal history, and then quenching the specimens to room temperature by immersion in ice. Specimens $1 \mathrm{~mm}$ thick were so obtained. Tests were also made by slowly cooling, at $10^{\circ} \mathrm{C} / \mathrm{min}$, the samples from the melt, but the results did not change with respect to the quenched ones. Samples for mechanical testing were prepared by injection molding, as described in paragraph 2.7 .

\subsection{Wide angle $\mathrm{X}$-ray diffraction}

WAXD patterns were recorded in the diffraction angular range $1.5-40^{\circ} 2 \theta$ by a Philips X'Pert PRO (Almelo, The Netherlands) diffractometer, working in the reflection geometry and equipped with a graphite monochromator on the diffracted beam $\left(\mathrm{CuK}_{\alpha}\right.$ radiation). Transmission patterns were also recorded in the diffraction range $5-40^{\circ} 2 \theta$ by a diffractometer GD 2000 (Ital Structures, Riva del Garda, Italy) working in a Seeman-Bohlin geometry and with a quartz crystal monochromator on the primary beam $\left(\mathrm{CuK}_{\alpha 1}\right.$ radiation). Results were the same either in the transmission and reflection mode, so it was concluded that no difference in structure and morphology existed in the samples between the bulk and the surface. The data presented in this paper were gathered in the reflection geometry. The application of the least-squares fit procedure elaborated by Hindeleh and Johnson [16] gave the degree of crystallinity by weight. The estimate of the degree of crystallinity was made after completion of the II $\rightarrow$ I phase transition, in order to rule out the effect of polymorphism and of the post crystallization, during which part of the amorphous polymer crystallizes in phase I $[17,18]$. The phase transition $\mathrm{II} \rightarrow \mathrm{I}$ was followed observing the WAXD patterns and estimating, as a function of time, the ratio $A_{\mathrm{t}} / A_{0}$, where $A_{\mathrm{t}}$ represents the area under the peak at $11.9^{\circ}$ $2 \theta$, i.e. the (200) reflection of phase II, at time $t$, and $A_{0}$ is the area of the same peak just after crystallization from the melt. Right after quenching from the melt, the samples were immediately mounted in the diffractometer, so the WAXD data at $t=0$ relative to the reflections above were acquired in 10 minutes.

\subsection{Small angle $X$-ray scattering}

The SAXS patterns of the samples were recorded by a MBraun (Graz, Austria) system, using a $\mathrm{CuK}_{\alpha}$ radiation from a Philips PW $1830 \mathrm{X}$-ray generator. The data were collected by a position sensitive detector and were successively corrected for blank scattering, desmeared and Lorentz-corrected.

A fitting method of SAXS patterns was developed on the basis of a theoretical model [19-23] referring to the Hosemann model [24], that assumes the presence of lamellar stacks having an infinite side dimension. This assumption takes into account a monodimensional electron density change along the normal direction to the lamellae.

\subsection{Transmission electron microscopy}

TEM analyses were performed by a Philips CM 120 (Eindhoven, The Netherlands). Samples were stained by $\mathrm{RuO}_{4}$ and cryomicrotomed. Sections about $100 \mathrm{~nm}$ thick were obtained and analyzed.

\subsection{Polarized light optical microscopy}

The spherulitic morphology of the samples was studied with a Leica DM400M (Wetzlar, Germany) polarized light microscope. The samples were placed between a glass slide and a cover slip and were kept at $170^{\circ} \mathrm{C}$ for $10 \mathrm{~min}$, to ensure uniform melting and to delete their thermal history. The slide was then transferred to a Mettler FP82HT (Columbus, OH, USA) hot stage set at $95^{\circ} \mathrm{C}$. Photomicrographs were taken between cross-polarizers with a Leica DFC280 (Wetzlar, Germany) digital camera. 


\subsection{Differential scanning calorimetry}

All the measurements were carried out with a TA Instruments mod. 2920 (New Castle, DE, USA) calorimeter operating under $\mathrm{N}_{2}$ atmosphere. Polymer samples weighing about $5 \mathrm{mg}$ closed in aluminum pans were used throughout the experiments. Indium of high purity was used for calibrating the DSC temperature and enthalpy scales. In order to determine the samples' crystallization temperature $\left(T_{\mathrm{c}}\right)$, their thermal history was cancelled by a $5 \mathrm{~min}$ long isotherm at $170^{\circ} \mathrm{C}$, subsequently the samples were cooled down to room temperature at $10^{\circ} \mathrm{C} / \mathrm{min}$. $T_{\mathrm{c}}$ was the temperature corresponding to the maximum in the exothermic peak.

\subsection{Physical mechanical properties}

The specimens for mechanical testing were prepared by injection molding in accordance with ISO 294, treated for 10 minutes in autoclave at 2000 bars and conditioned for $40 \mathrm{~h}$ at $23 \pm 2^{\circ} \mathrm{C}$ and $50 \pm 5 \%$ relative humidity following ISO 291. All the samples were prepared with the same processing parameters to allow a proper comparison, because the preparation step affects the resulting properties. All the mechanical tests were performed after completion of the II $\rightarrow$ I phase transition. The flexural and elongational properties were determined in accordance with ISO 178 using a Model 4301 instrument (Instron, Norwood, MA, USA) on injection moulded specimens, prepared following ISO 294-1 (length = $80 \pm 2 \mathrm{~mm}$, width $=10 \pm 0.2 \mathrm{~mm}$ and thickness $=$ $4.0 \pm 0.2 \mathrm{~mm}$ ).

Impact strength was measured with a 6545 pendulum-type hammer (Ceast, Pianezza, Italy) striking a notched specimen with a $0.05 \mathrm{~mm}$ notch (ISO 180).

\section{Results}

Table 1 summarizes the composition of the considered samples. The formulation of the specimens allowed also to study the effect of compatibilization, because 4 of the composite samples were compatibilized with an amount of polypropylene grafted with maleic anhydride (PP-g-MA) $(1 \% \mathrm{w} / \mathrm{w})$ equal to that of perkalite, whereas two of the composites did not contain any compatibilizer. The polymeric matrix will be designated in the rest of this paper as PB0. One of the aims was in fact to investigate if these different formulations could attain different

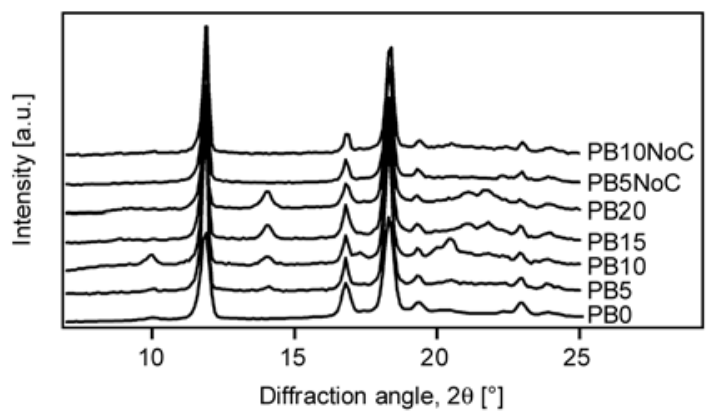

Figure 1. WAXD patterns of the samples at $t=0$

composite morphologies and dispersions of the filler in the matrix, therefore studying its effect on the polymer semicrystalline framework and on the rate of phase transformation. The morphology of the composite was in fact shown to be key for the property improvement, for the stability of the metastable phase and also for the acceleration of the rate of the $\mathrm{II} \rightarrow \mathrm{I}$ transition [4-7].

WAXD was used to follow the phase transition, acquiring diffractograms at different times after cooling from the melt. Figure 1 shows the WAXD patterns at $t=0$, i.e. immediately after quenching from the melt, of the considered samples. The reflections relative to the tetragonal phase II are three main peaks at $11.9,16.9$ and $18.4^{\circ} 2 \theta$, due to the (200), (220) and (301) planes. The hexagonal phase I is characterized by four signals at 9.9, 17.3, 20.2 and $20.5^{\circ} 2 \theta$, originated by the (110), (300), (220) and (211) planes [25].

Mixed I/II polymorphism is displayed just by sample PB10, and to a lesser extent by PB5 and PB0. In these samples, a small amount of phase I is present since time 0 , as especially evidenced by the small (110) peak visible at $9.9^{\circ} 2 \theta$. It has already been noted that in PB-based nanocomposites filled with layered silicates, some phase I can coexist with phase II right after cooling from the melt. This is due to the appearance of a defective population of phase II crystals, which very rapidly transforms into phase I [7, 25, 26]. All the other samples showed, right after melting, $100 \%$ phase II.

In Figure 1, an increasing peak located at $14.1^{\circ} 2 \theta$ is evident in the samples containing the largest amounts of clay. This is ascribable to the increasing quantity of PP-MA compatibilizer, and corresponds to the (110) peak of the $\alpha$ phase of polypropylene. The presence of this compatibilizer should therefore be 
taken into account as a material seriously capable to influence the structure, material and properties of the composites.

Figure 2a shows an example, for sample PB10, of the evolution of the WAXD patterns as a function of time. Analyzing these diffractograms, it was possible to follow and quantify the kinetics of phase transformation in the studied samples. Figure $2 b$ shows for example the rate of disappearance of phase II as a function of time, extracted from the data in Figure 2a. For the quantification of the kinetics of the II $\rightarrow$ I phase transition, the disappearance of phase II, rather than the increase in phase I, was followed because it is known that, together with the phase transition, a post-crystallization phenomenon takes place, during which part of the amorphous polymer crystallizes in phase I $[17,18$, $25,27]$. The calculations were also done consider-
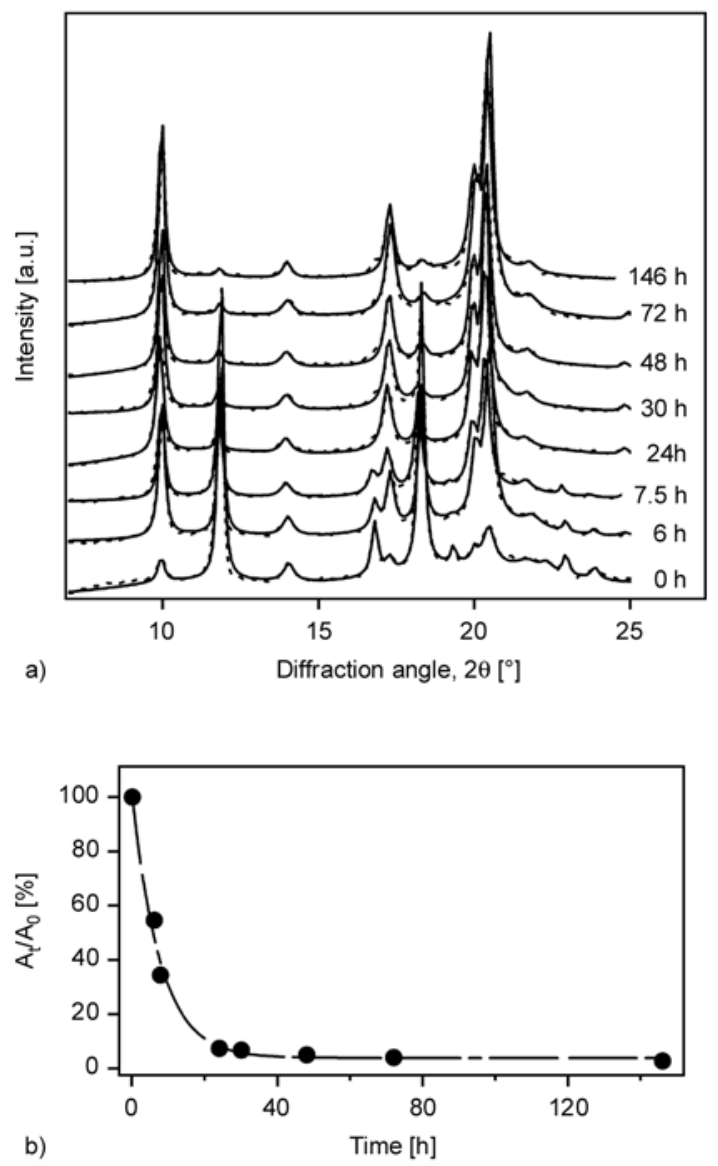

Figure 2. a) WAXD patterns of sample PB10 at different aging times, experimental patterns are shown by dotted lines, the fitting functions are shown by solid lines; b) Percent change, as a function of time, of the (200) peak area. The line indicates the exponential fitting function used to determine the half time of transformation.
Table 2. Crystallinity, evaluated by WAXD, $\varphi_{\text {WAXD }}$, of the studied samples at time 0 and after 5 days

\begin{tabular}{|l|c|c|}
\hline \multicolumn{1}{|c|}{ Sample } & $\boldsymbol{\varphi}_{\text {WAXD }}$ at time 0 [\%] & $\boldsymbol{\varphi}_{\text {WAXd }}$ after 120 h [\%] \\
\hline PB0 & 66 & 76 \\
\hline PB5 & 53 & 63 \\
\hline PB10 & 50 & 57 \\
\hline PB15 & 49 & 59 \\
\hline PB20 & 43 & 55 \\
\hline PB5NoC & 49 & 60 \\
\hline PB10NoC & 45 & 63 \\
\hline
\end{tabular}

ing the amount of phase II as a ratio of the sum of the peaks of phases I and II [25], obtaining analogous results because the initial amount of phase I was almost always negligible. Table 2 shows the trend of the degree of crystallinity measured on the samples before and after the phase transition, and Figure 3 shows the evolution of crystallinity as a function of time for sample PB5. A clear increase in the crystallinity can be observed, confirming that a post-crystallization process indeed happens. An increase in crystallinity occurs with aging time, reaching a plateau around $70 \mathrm{~h}$.

On the basis of diagrams such as those displayed in Figure $2 b$, the half time of II $\rightarrow$ I phase transition, $t_{1 / 2}$, could be assessed. The experimental points were fitted with an exponential function (also displayed in Figure $2 b$ ). The analytical function so obtained was used to calculate $t_{1 / 2}$, i.e the time needed to reduce by $50 \%$ the initial phase II content. Table 3 shows the $t_{1 / 2}$ for the studied samples. For comparison purposes, in this same table the $t_{1 / 2}$ for a composite based on the same PB matrix containing 5\% montmorillonite clay and 7\% compatibilizer is also shown (this sample is labeled PB5M in Table 3 and further details on this sample can be found in Ref. 6). This sample is a suitable benchmark for assessing the role of perkalite, because it displayed a morphology of clay dispersion very similar to the one detected in the samples described

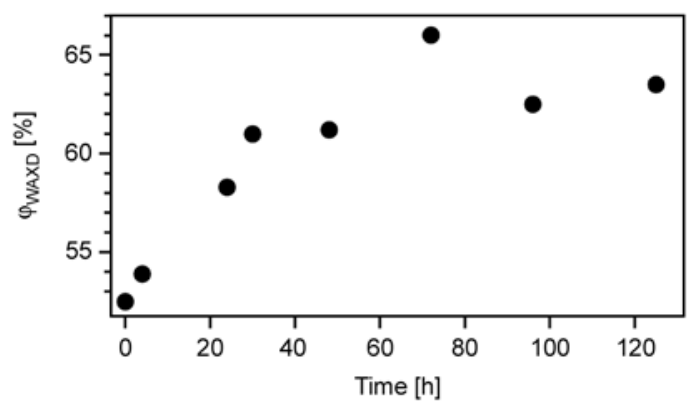

Figure 3. Evolution as a function of time of the crystallinity, evaluated by WAXD, for sample PB5 
Table 3. Half time of the II $\rightarrow$ I phase transformation and residual phase II remaining after 5 days

\begin{tabular}{|l|r|c|}
\hline \multicolumn{1}{|c|}{ Sample } & $\mathbf{t}_{\mathbf{1} / \mathbf{2}}[\mathbf{h} \boldsymbol{1}$ & Residual phase II \\
\hline PB0 & 13.5 & $6 \%$ \\
\hline PB5 & 5.8 & $5 \%$ \\
\hline PB10 & 5.7 & $4 \%$ \\
\hline PB15 & 16.6 & $7 \%$ \\
\hline PB20 & 16.7 & $9 \%$ \\
\hline PB5NoC & 16.5 & $11 \%$ \\
\hline PB10NoC & 15.5 & $11 \%$ \\
\hline PB5M & 2.2 & $3 \%$ \\
\hline
\end{tabular}

in this work: a reduction in tactoid size, with some degree of intercalation [6].

Two groups of samples can be identified. The composites containing the lesser amount of perkalite, PB5 and PB10, displayed a sharp increase in the rate of phase transition, with a much reduced $t_{1 / 2}$ with respect to that of pristine PB. It is also worth noting that some residual phase II remained after 5 days, indicating that the phase transformation does not go to completion. The lowest amounts of residual phase II was observed in samples PB5 and $\mathrm{PB} 10$, i.e. those with the fastest $\mathrm{II} \rightarrow \mathrm{I}$ phase transition.

As will be better detailed in the discussion section of this paper, in order to better interpret the reasons of these increases in the rate of phase transformation, it is necessary to thoroughly characterize the structure and morphology of the composites.

The effect of clay on the regular arrangement of the semicrystalline framework can be assessed by the trend of the degrees of crystallinity in Table 2. A decrease in $\varphi_{\text {WAXD }}$ can be observed before and after the phase transformation. The detrimental effect of clay on the regularity of the crystalline cell is well known [3, 28-30]. The disruptive effect of clay was not limited to the crystalline cell, but it extended also to the lamellar morphology, as evidenced by SAXS data. Figure 4 shows the SAXS patterns obtained for the considered samples. The neat PB matrix shows a quite defined peak whereas, with an

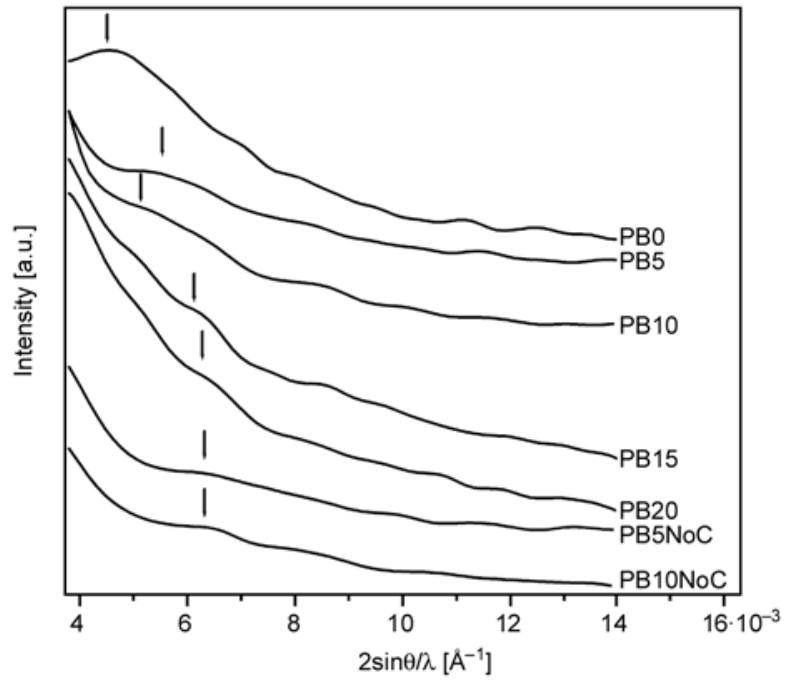

Figure 4. SAXS patterns of the considered samples in the polymer lamellar periodicity region. The arrows indicate the position of the peak maximum.

increasing perkalite content, such peak becomes weaker and shifts progressively towards wider angles. The experimental traces due to the matrix and to the composite samples were fitted according to a method [19, 20, 24] which was shown [23] to reliably determine the thicknesses and distributions of the crystalline and amorphous layers, the long period and the crystallinity, along with their distribution, associated to lamellar stacks. The results are shown in Table 4. The patterns relative to samples PB15 and PB20 had signals so weak that they could not be fitted. The data in Table 4 confirm the shift of the long period that could be qualitatively detected on the SAXS traces. It is interesting to note that the samples with the lowest degree of crystallinity as measured by SAXS were PB5 and PB10, i.e. those with the fastest phase transition. Comparing the data in Tables 2 and 4, it can be seen that the crystallinities assessed by SAXS have larger values relative to those estimated by WAXD. This divergence can be explained considering the difference between the two techniques. SAXS is only sensitive to the crystalline regions organized in lamellar stacks,

Table 4. Morphological parameters of the lamellar stacks obtained by SAXS analysis of the samples. The thickness of the crystalline $(C)$ and amorphous layer $(A)$, the long period $(D)$, and the crystallinity $\left(\varphi_{\mathrm{SAXS}}\right)$, along with their relative distributions $\left(\sigma_{\mathrm{c}} / C=\sigma_{\mathrm{A}} / \mathrm{A}, \sigma_{\mathrm{D}} / \mathrm{D}\right)$, and number of lamellae $(N)$ are shown

\begin{tabular}{|l|c|c|c|c|c|c|c|c|}
\hline \multicolumn{1}{|c|}{ Sample } & $\mathbf{C}[\AA]$ & $\boldsymbol{\sigma}_{\mathbf{C}} / \mathbf{C}$ & $\mathbf{A}[\boldsymbol{\AA}]$ & $\boldsymbol{\sigma}_{\mathbf{A}} / \mathbf{A}$ & $\mathbf{D}[\AA]$ & $\boldsymbol{\sigma}_{\mathbf{D}} / \mathbf{D}$ & $\boldsymbol{\Phi}_{\text {SAXs }}[\mathbf{\%}]$ & $\mathbf{N}$ \\
\hline PB0 & 181 & 0.43 & 59 & 0.43 & 240 & 0.34 & 76 & 5 \\
\hline PB5 & 122 & 0.42 & 52 & 0.42 & 174 & 0.32 & 70 & 2 \\
\hline PB10 & 133 & 0.49 & 61 & 0.49 & 194 & 0.37 & 68 & 3 \\
\hline PB05NoC & 110 & 0.26 & 42 & 0.26 & 152 & 0.20 & 72 & 3 \\
\hline PB10NoC & 111 & 0.31 & 41 & 0.31 & 152 & 0.24 & 73 & 3 \\
\hline
\end{tabular}


whereas WAXD allows the detection of all the regions contributing to the semicrystalline framework, including the amorphous phase located between the lamellar stacks. Therefore WAXD crystallinity is lower because the contribution of crystalline domains is 'diluted' by the interstack amorphous parts.

It is also striking that all the samples, including PB0, have an extremely low average number of lamellae per stack, which decreases with increasing perkalite content.

A further observation that can be made on the data in Table 4 is that the distribution of the thicknesses of the crystalline $\left(\sigma_{\mathrm{C}} / C\right)$ and amorphous layers $\left(\sigma_{\mathrm{A}} / A\right)$, and of the long period $\left(\sigma_{\mathrm{D}} / D\right)$ is broadened by an increasing perkalite content, when the compatibilizer is used. On the other hand, in the uncompatibilized composites such distribution is significantly narrower than that of the matrix. Apparently the presence of the compatibilizer poses an obstacle to the regularity of the lamellar stacks and to the homogeneous distribution of the layers which compose the stacks.

WAXD and SAXS were used to evaluate the degree of dispersion of clay in the polymer matrix. Figure 5 and 6 show the results of such analyses. Neat clay displays, both in WAXD and SAXS, a single peak correspondent to a $d$-spacing of $36 \AA$, which should be attributed to the reflections from the (003) family of crystallographic planes [31]. The $d_{003}$ can be termed the interlayer spacing and includes a contribution from the metal hydroxide layer and the gallery that contains the intercalated anions [31]. It may be seen in Figure 5 that the basal peaks of clay in the composites are not significantly shifted with respect to that of pristine clay. The periodicity

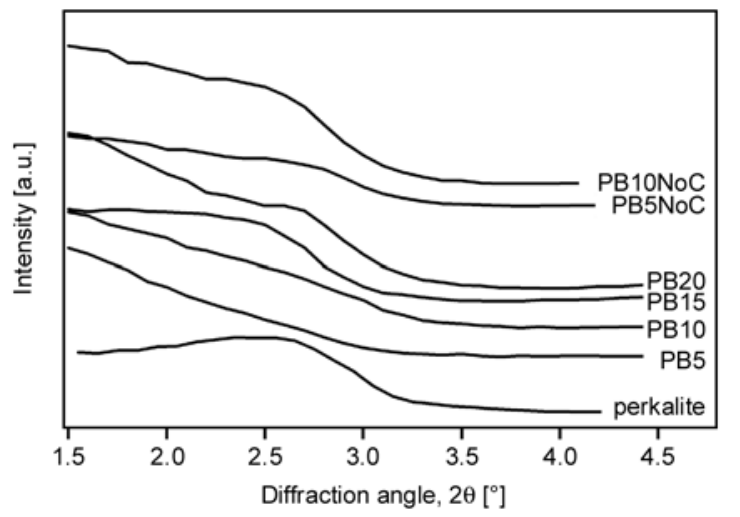

Figure 5. WAXD patterns of the considered samples in the angular region of the basal planes

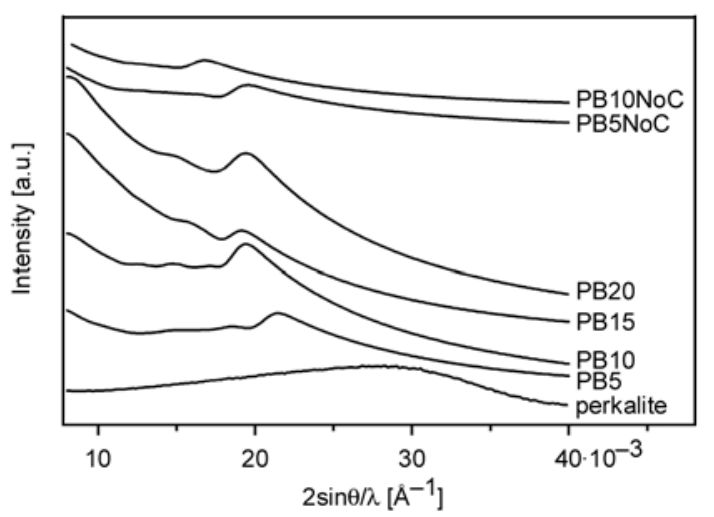

Figure 6. SAXS patterns of the considered samples in the clay periodicity region

values obtained from the position of the basal peaks are quite constant throughout the samples and are all equal to about $35 \AA$. This is consistent with the presence of a non-intercalated population of tactoids which retains the interlayer spacing of pristine clay.

SAXS allowed to complement this information, investigating a range of interlayer distances beyond the low angle limit of WAXD. In Figure 6 SAXS spectra gathered on the composites are shown, along with the SAXS pattern of neat perkalite. It is known that the width of diffraction peaks is related to the size of the diffracting domains. The basal peaks detected by WAXD were very broad, indicative of rather small non-intercalated tactoids. Such small tactoids did not produce a signal intense enough to be detected by SAXS in an angular position close to the wide-angle limit of SAXS, so the non-intercalated population of tactoids was not visible in the SAXS traces. On the other hand, neat perkalite yielded a detectable SAXS signal located at about $30 \AA^{-1}$ because the pristine filler has very large and very ordered tactoids, which give rise to a rather intense SAXS peak. SAXS evidenced that, along with the non-intercalated tactoid population observed by WAXD, another population was present, which was composed by intercalated tactoids. A clear shift in the SAXS peak is observed for the composites with respect to the neat perkalite, indicating a significant degree of intercalation. A quantitative estimation of the average size of the clay stacks was performed by fitting procedures of the SAXS traces. On the basis of theoretical models which are functions of the morphological features of tactoids, calculated SAXS spectra were generated to reproduce 


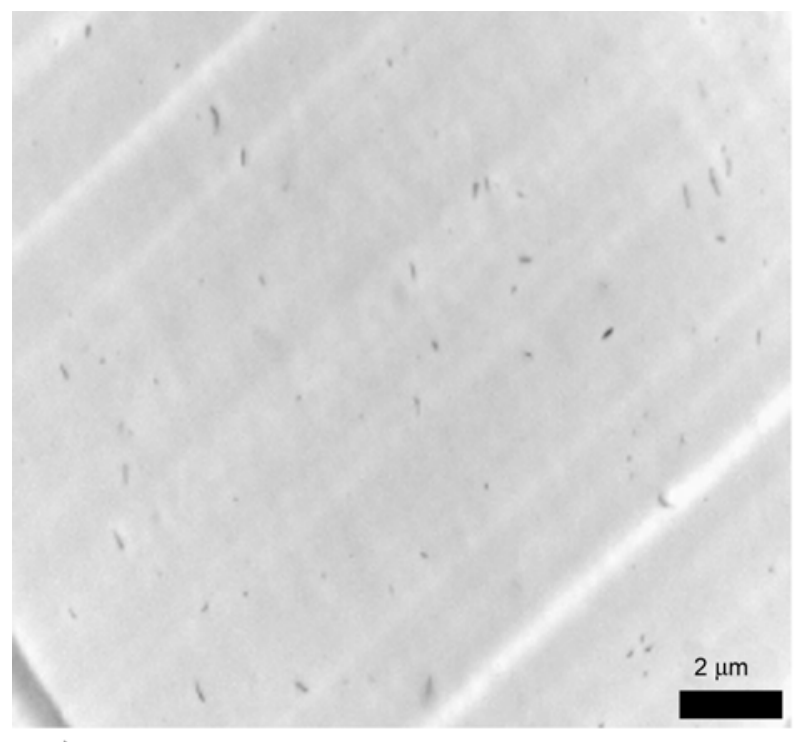

a)

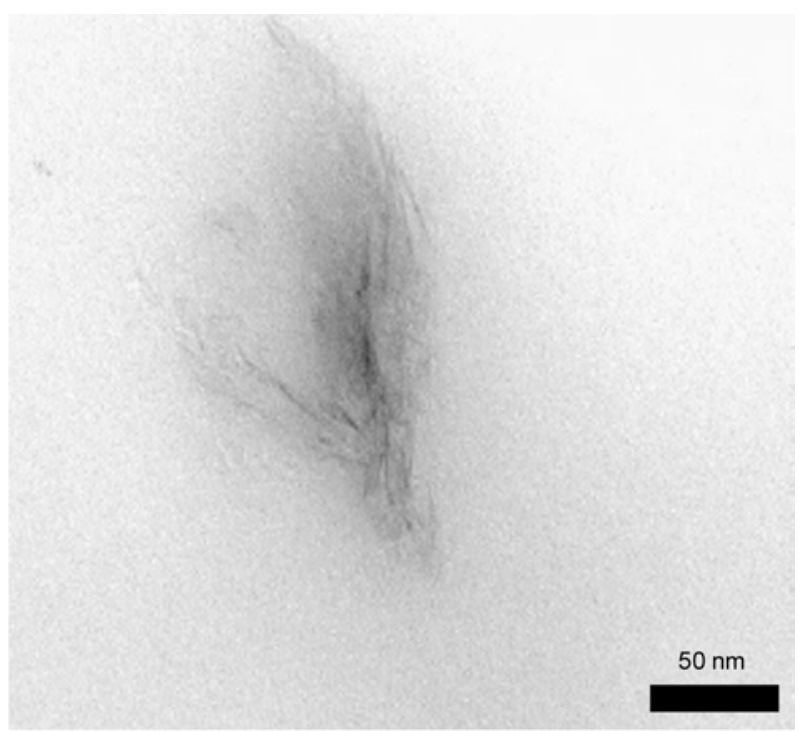

b)

Figure 7. TEM micrograph of sample PB5 at different magnifications

experimental ones, allowing an evaluation of the mean number of layers, their spacing and distribution [22]. The fitting showed that the average number of layers per each intercalated stack was about 5 for all the composites, indicating a significant degree of interaction between polymer and filler. TEM was used to complement and to amend one of the limitations of SAXS, i.e. that SAXS alone is not able to assess the proportion of intercalated tactoids, with respect to the total amount of clay. TEM confirmed that clay is not exfoliated. However, low and high magnification TEM micrographs showed that the size of tactoids is very small, coherently with SAXS data (Figure 7). It has been argued that this latter

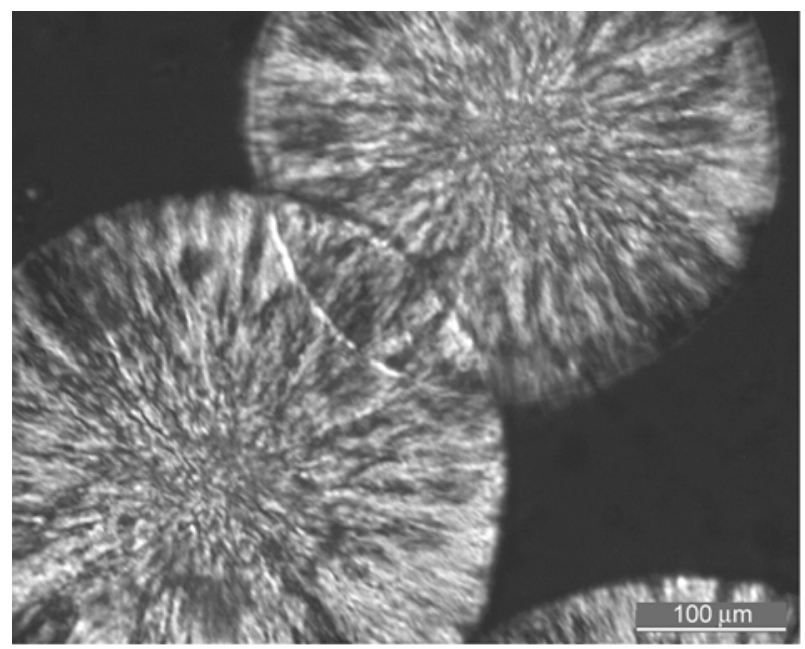

a) situation, i.e. reduction of the size of tactoids to just two or three layers, can be considered practically equivalent to exfoliation, as far as properties are concerned [6, 30, 32-34].

The nucleation behavior of perkalite was also studied, by DSC and PLOM. Figure 8 displays two exemplary micrographs of samples PB0 and PB5 which show that the size of spherulites after 10 minutes of isothermal crystallization at $95^{\circ} \mathrm{C}$ was much larger in the neat matrix, than in the composites. This is due to the nucleating ability of perkalite, which was confirmed by the increase in the non-isothermal crystallization temperature measured by DSC. In fact, in the cooling ramp from the melting tempera-

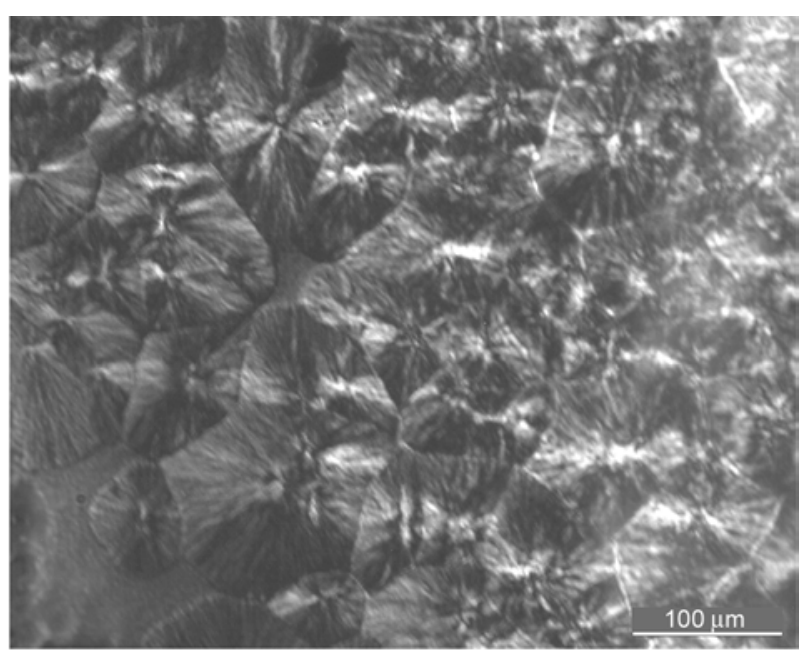

b)

Figure 8. PLOM micrographs of the spherulites obtained after 10 minutes of isothermal crystallization at $95^{\circ} \mathrm{C}$ for samples a) PB0 and b) PB5 
ture to room temperature, the position of the crystallization peak shifted from $76^{\circ} \mathrm{C}$ of $\mathrm{PB} 0$ to $88^{\circ} \mathrm{C}$ of the composites.

The physical mechanical properties were extremely similar to those measured on analogous montmorillonite-containing samples (Table 5) [6]. With increasing perkalite content, an increase in modulus was observed, up to an improvement, in sample PB20, of $81 \%$ with respect to the neat matrix. This higher rigidity of the samples, though, was obtained at the expense of ductility, because the impact strength and the elongation at break severely decreased as a function of perkalite content.

\section{Discussion}

Poly(1-butene) is an interesting polymer for the scientific community and for the industry because it displays very promising physical mechanical properties, at the same time suffering the drawback of a slow phase transition which so far reduced its applicative potential.

The purpose of this paper was to contribute in shedding light on the relationship between the morphology of poly(1-butene)-layered silicate nanocomposites and the rate of $\mathrm{II} \rightarrow \mathrm{I}$ phase transition.

In this work, it was seen that the compatibilized composites with a low perkalite content, i.e. samples PB5 and PB10, have a much faster II $\rightarrow$ I phase transition with respect to the pure PB matrix. Comparing the results obtained in this work with analogous composites prepared by adding montmorillonite clay (Table 3), it can be seen that the half-time of transformation is just $2.2 \mathrm{~h}$ with montmorillonite, and $5.7 \mathrm{~h}$ for perkalite. The half-time of $\mathrm{II} \rightarrow \mathrm{I}$ phase transition of pure PB was $13.5 \mathrm{~h}$. Montmorillonite is therefore more efficient than perkalite in increasing the rate of phase transition.

Previous results indicated that the phase diagram of poly(1-butene) depends on the balance between homogeneity of the system and rate and regularity of crystallization [7]. In cases like this of poly(1butene), the Ostwald's rule [35] is valid, which states that phase transformations will always proceed through stages of metastable states whenever these exist. In such cases, the crystallization pathway involves the formation of the nuclei in the metastable phase, followed by growth in this phase and eventually by a transition into the stable form $[36,37]$. The stability of such metastable state is critically dependent on the relative free energy content of the liquid (melt), metastable (phase II) and stable (phase I) crystal phases. Events that decrease the entropy of the melt (i.e. stiffening of the chains, orientation or formation of mesophases), or that increase the free energy of the crystalline phase (i.e. decrease of crystal perfection or reduction of crystal size) modify the region of existence of the metastable phase [36] and have therefore important consequences on the kinetics of the transformations also, because they influence the size of the critical nuclei $[36,37]$.

High pressure treatments, that act on the entropy of the melt, are industrially employed to quickly transform PB into phase I. At a molecular level, it has been argued that the stress exerted by the amorphous layers or tie molecules on the crystalline cores accelerates the phase transition [38, 39]. Layered silicates, which are usually preferentially distributed in the amorphous phase within spherulites [40-42], were shown to partly mimic this entropic effect by locally increasing the pressure on the nascent crystalline domains [7]. It was observed that large montmorillonite aggregates were desirable in delivering this effect, because small tactoids are too flexible and they are not able to exert pressure on the macromolecular chains [43-45]. This is confirmed by our results. All the composites had small tactoids, with an average number of layers per tactoid of just 5. Moreover, perkalite layers, as those of other layered double hydroxides, are more fragile in nature than montmorillonite-type clays [46-48], and so they are less able to put pressure on the nascent crystalline domains, and so they increase the rate of II $\rightarrow$ I phase transition less than bulkier montmorillonite tactoids.

Concurrently with the effect on the entropy of the melt, the filler also affects the free energy of the crystalline phase. Perkalite, like montmorillonite clay, exerts this role by decreasing the perfection of the crystals, as reflected by the above reported decrease in the degree of crystallinity found by WAXD and SAXS, with respect to the neat matrix. Rather than the disruption of the regular ordering at a crystalline cell level, the effect on the lamellar morphology seems to be preponderant. The crystallinity associated to the lamellar stacks, $\varphi_{\mathrm{SAXS}}$, is lower in samples PB5 and PB10, whereas it increases in $\mathrm{PB} 5 \mathrm{NoC}$ and $\mathrm{PB} 10 \mathrm{NoC}$, with a trend that reflects 
Table 5. Physical mechanical properties of the considered samples. FEM = flexural modulus, Izod = Izod impact test, $\mathrm{StBr}=$ stress at break, $\mathrm{ElBr}=$ elongation at break, HDT $=$ heat deflection test

\begin{tabular}{|l|c|c|c|c|c|c|}
\hline \multicolumn{1}{|c|}{ Sample } & FEM [MPa] & Izod $\left[\mathbf{k J} / \mathbf{m}^{2}\right.$ ] & Izod 0 ${ }^{\circ} \mathbf{C}\left[\mathbf{k J} / \mathbf{m}^{2}\right]$ & $\mathbf{S t B r}[\mathbf{M P a}]$ & $\mathbf{E I B r}[\%]$ & HDT $\left[{ }^{\circ} \mathbf{C}\right]$ \\
\hline PB0 & 549 & 6.0 & 3.4 & 25 & 225 & 110 \\
\hline PB5 & 600 & 5.4 & 2.4 & 21 & 100 & 109 \\
\hline PB10 & 712 & 3.2 & 2.3 & 21 & 57 & 109 \\
\hline PB15 & 815 & 2.5 & 1.4 & 21 & 11 & 106 \\
\hline PB20 & 995 & 2.0 & 1.3 & 20 & 3 & 103 \\
\hline PB5NoC & 555 & 8.8 & 3.9 & 25 & 250 & 110 \\
\hline PB10NoC & 647 & 6.8 & 3.1 & 20 & 92 & 109 \\
\hline
\end{tabular}

the II $\rightarrow$ I phase transition half-times. Moreover, a disturbing effect due to the presence of the compatibilizer was observed, which was reflected by a broadening of the distribution of the thicknesses of the lamellar stacks. This explains why larger amounts of perkalite, i.e. samples PB15 and PB20, and the absence of compatibilizer, i.e. $\mathrm{PB} 5 \mathrm{NoC}$ and PB10NoC, proved to be detrimental for the rate of phase transition: the $t_{1 / 2}$ was comparable to that for the neat PB matrix. Thus, although a blank poly(1butene)/compatibilizer sample with no clay was not prepared and analyzed in this work, on the basis of our data we could infer that the compatibilizer does not favor an increase of the rate of II $\rightarrow$ I phase transition, confirming what was already reported elsewhere in the case of montmorillonite-based composites [7]. This large effect of the crystallinity at a lamellar level is also in agreement and contributes to explain previously reported results, according to which the nucleation centers of the II $\rightarrow$ I phase transition are located in the lamellar distortion points $[17,49]$, i.e. larger inhomogeneity in the lamellar structure brings about the earlier appearance of phase I domains.

\section{Conclusion}

Nanocomposite samples were prepared by adding perkalite to a matrix of poly(1-butene), in order to study the effect of this particular kind of clay on the rate of $\mathrm{II} \rightarrow \mathrm{I}$ phase transition of the matrix. Perkalite was found to increase the rate of II $\rightarrow$ I phase transition with respect to the neat matrix, albeit less dramatically than montmorillonite. The fragility of perkalite layers and the substantial reduction of the tactoids did not allow to influence the entropic factor to the phase diagram of poly(1-butene), because the filler was not able to locally increase the pressure on the nascent crystalline domains.
The reduction of the size of perkalite tactoids confirmed that poly(1-butene) is very efficient in homogeneously dispersing the filler, thereby justifying the use of the materials produced in the present study as viable masterbatches for the production of polyolefin-based nanocomposites. Therefore, a further development of this work, which will be more completely discussed in a further article, will be to exploit the good propensity of poly(1-butene) in dispersing layered fillers more efficiently than other polyolefins, and to use these materials as masterbatches for the preparation of polymer nanocomposites with a polypropylene matrix.

\section{Acknowledgements}

Ramesh Neppalli is grateful to Fondazione Cassa di Risparmio di Padova e Rovigo for the support of his $\mathrm{PhD}$ grant.

\section{References}

[1] Azzurri F., Flores A., Alfonso G. C., Baltá Calleja F. J.: Polymorphism of isotactic poly(1-butene) as revealed by microindentation hardness. 1 . Kinetics of the transformation. Macromolecules, 35, 9069-9073 (2002). DOI: $10.1021 / \mathrm{ma} 021005 \mathrm{e}$

[2] Kaszonyiova M., Rybnikar F., Geil P. H.: Crystallization and transformation of polybutene-1. Journal of Macromolecular Science Part B: Physics, 43, 10951114 (2004). DOI: $10.1081 / \mathrm{MB}-200033322$

[3] Wanjale S. D., Jog J. P.: Poly (1-butene)/clay nanocomposites: A crystallization study. Journal of Macromolecular Science Part B: Physics, 42, 1141-1152 (2003). DOI: $10.1081 / \mathrm{MB}-120024810$

[4] Wanjale S. D., Jog J. P.: Poly(1-butene)/clay nanocomposites: Preparation and properties. Journal of Polymer Science Part B: Polymer Physics, 41, 1014-1021 (2003).

DOI: $10.1002 /$ polb.10418 
[5] Nathani H., Dasari A., Misra R. D. K.: On the reduced susceptibility to stress whitening behavior of melt intercalated polybutene-clay nanocomposites during tensile straining. Acta Materialia, 52, 3217-3227 (2004). DOI: $10.1016 /$ j.actamat.2004.03.021

[6] Causin V., Marega C., Marigo A., Ferrara G., Idiyatullina G., Fantinel F.: Morphology, structure and properties of a poly(1-butene)/montmorillonite nanocomposite. Polymer, 47, 4773-4780 (2006).

DOI: $10.1016 /$ j.polymer.2006.04.035

[7] Marega C., Causin C., Marigo A., Saini R., Ferrara G.: Crystallization of a (1-butene)-ethylene copolymer in phase I directly from the melt in nanocomposites with montmorillonite. Journal of Nanoscience and Nanotechnology, 10, 3078-3084 (2010).

DOI: $10.1166 /$ jnn.2010.2184

[8] Leroux F.: Organo-modified anionic clays into polymer compared to smectite-type nanofiller: Potential applications of the nanocomposites. Journal of Nanoscience and Nanotechnology, 6, 303-315 (2006).

DOI: $10.1166 /$ jnn.2006.003

[9] Chen W., Qu B. J.: Structural characteristics and thermal properties of PE-g-MA/MgAl-LDH exfoliation nanocomposites synthesized by solution intercalation. Chemistry of Materials, 15, 3208-3213 (2003). DOI: $10.1021 / \mathrm{cm} 030044 \mathrm{~h}$

[10] Li B., Hu Y., Zhang R., Chen Z., Fan W. C.: Preparation of the poly(vinyl alcohol)/layered double hydroxide nanocomposite. Materials Research Bulletin, 38, 1567-1572 (2003).

DOI: 10.1016/S0025-5408(03)00203-4

[11] Wang G-A., Wang C-C., Chen C-Y.: The disorderly exfoliated LDHs/PMMA nanocomposite synthesized by in situ bulk polymerization. Polymer, 46, 50655074 (2005).

DOI: 10.1016/j.polymer.2005.04.054

[12] Marega C., Causin V., Marigo A., Ferrara G., Tonnaer H.: Perkalite as an innovative filler for isotactic polypropylene-based nanocomposites. Journal of Nanoscience and Nanotechnology, 9, 2704-2714 (2009). DOI: $10.1166 /$ jnn.2009.dk01

[13] Benetti E. M., Causin V., Marega C., Marigo A., Ferrara G., Ferraro A., Consalvi M., Fantinel F.: Morphological and structural characterization of polypropylene based nanocomposites. Polymer, 46, 8275-8285 (2005).

DOI: $10.1016 /$ j.polymer.2005.06.056

[14] Ciardelli F., Coiai S., Passaglia E., Pucci A., Ruggeri G.: Nanocomposites based on polyolefins and functional thermoplastic materials. Polymer International, 57, 805-836 (2008).

DOI: $10.1002 /$ pi.2415

[15] Broekaert C., Peeterbroeck S., Benali S., Monteverde F., Bonnaud L., Alexandre M., Dubois P.: Chlorinated polyethylene/layered silicate nanocomposites: Poly( $\varepsilon-$ caprolactone)-based 'masterbatch' approach. European Polymer Journal, 43, 4160-4168 (2007).

DOI: $10.1016 /$ j.eurpolymj.2007.08.003
[16] Hindeleh A. M., Johnson D. J.: The resolution of multipeak data in fibre science. Journal of Physics D: Applied Physics, 4, 259-263 (1971).

DOI: $10.1088 / 0022-3727 / 4 / 2 / 311$

[17] Marigo A., Marega C., Cecchin G., Collina G., Ferrara G.: Phase transition II $\rightarrow$ I in isotactic poly-1-butene: Wide- and small-angle X-ray scattering measurements. European Polymer Journal, 36, 131-136 (2000). DOI: 10.1016/S0014-3057(99)00043-9

[18] Zannetti R., Manaresi P., Buzzoni G. C.: Crystallinity and polymorphism of poly- $\alpha$-butene (in Italian). $\mathrm{La}$ Chimica e l'Industria, 43, 735-740 (1961).

[19] Blundell D. J.: Models for small-angle X-ray scattering from highly dispersed lamellae. Polymer, 19, 1258-1266 (1978).

DOI: 10.1016/0032-3861(78)90302-6

[20] Marega C., Marigo A., Cingano G., Zannetti R., Paganetto G.: Small-angle X-ray scattering from highdensity polyethylene: Lamellar thickness distributions. Polymer, 37, 5549-5557 (1996).

DOI: $10.1016 / \mathrm{S} 0032-3861(96) 80440-\mathrm{X}$

[21] Marega C., Marigo A., Causin V.: Small-angle X-ray scattering from polyethylene: Distorted lamellar structures. Journal of Applied Polymer Science, 90, 24002407 (2003).

DOI: $10.1002 / a p p .12890$

[22] Causin V., Marega C., Marigo A., Ferrara G.: Assessing organo-clay dispersion in polymer layered silicate nanocomposites: A SAXS approach. Polymer, 46, 9533-9537 (2005).

DOI: 10.1016/j.polymer.2005.08.034

[23] Marega C., Causin V., Marigo A.: A SAXS-WAXD study on the mesomorphic- $\alpha$ transition of isotactic polypropylene. Journal of Applied Polymer Science, 109, 32-37 (2008).

DOI: 10.1002/app.28017

[24] Hosemann R., Bagchi S. N.: Direct analysis of diffraction by matter. North Holland, Amsterdam (1962).

[25] Azzurri F., Alfonso G. C., Gómez M. A., Martì M. C., Ellis G., Marco C.: Polymorphic transformation in isotactic 1-butene/ethylene copolymers. Macromolecules, 37, 3755-3762 (2004).

DOI: $10.1021 / \mathrm{ma} 0358327$

[26] Azzurri F., Gómez M. A., Alfonso G. C., Ellis G., Marco C.: Time-resolved SAXS/WAXS studies of the polymorphic transformation of 1-butene/ethylene copolymers. Journal of Macromolecular Science Part B: Physics, 43, 177-189 (2004).

DOI: $10.1081 / \mathrm{MB}-120027757$

[27] Asada T., Sasada J., Onogi S.: Rheo-optical studies of high polymers. XXI. The deformation process and crystal transformation in polybutene-1. Polymer Journal, 3, 350-356 (1972).

DOI: $\underline{10.1295 / \text { polymj. } 3.350}$ 
[28] Ma J., Zhang S., Qi Z., Li G., Hu Y.: Crystallization behaviors of polypropylene/montmorillonite nanocomposites. Journal of Applied Polymer Science, 83, 1978-1985 (2002).

DOI: $10.1002 / a p p .10127$

[29] Hambir S., Bulakh N., Jog J. P.: Polypropylene/clay nanocomposites: Effect of compatibilizer on the thermal, crystallization and dynamic mechanical behavior. Polymer Engineering and Science, 42, 1800-1807 (2002).

DOI: $10.1002 /$ pen.11072

[30] Causin V., Marega C., Marigo A., Ferrara G., Ferraro A., Selleri R.: Structure-property relationships in isotactic poly(propylene)/ethylene propylene rubber/ montmorllonite nanocomposites. Journal of Nanoscience and Nanotechnology, 8, 1823-1834 (2008).

DOI: $10.1166 /$ jnn.2008.0031823

[31] Wilson O. C., Olorunyolemi T., Jaworski A., Borum L., Young D., Siriwat A., Dickens E., Oriakhi C., Lerner M.: Surface and interfacial properties of polymer-intercalated layered double hydroxide nanocomposites. Applied Clay Science, 15, 265-279 (1999). DOI: $10.1016 / \mathrm{S} 0169-1317(99) 00023-\mathrm{X}$

[32] Mehta S., Mirabella F. M., Rufener K., Bafna A.: Thermoplastic olefin/clay nanocomposites: Morphology and mechanical properties. Journal of Applied Polymer Science, 92, 928-936 (2004).

DOI: $10.1002 / a p p .13693$

[33] Fasulo P. D., Rodgers W. R., Ottaviani R. A., Hunter D. L.: Extrusion processing of TPO nanocomposites. Polymer Engineering and Science, 44, 1036-1045 (2004). DOI: $10.1002 /$ pen.20097

[34] Zhang Z., Zhang L., Li Y., Xu H.: New fabricate of styrene-butadiene rubber/montmorillonite nanocomposites by anionic polymerization. Polymer, 46, 129136 (2005).

DOI: $10.1016 /$ j.polymer.2004.11.008

[35] Ostwald W.: The formation and changes of solids. Zeitschrift für Physikalische Chemie, 22, 286-330 (1897).

[36] Keller A., Hikosaka M., Rastogi S., Toda A., Barham P. J., Goldbeck-Wood G.: An approach to the formation and growth of new phases with application to polymer crystallization: Effect of finite size, metastability, and Ostwald's rule of stages. Journal of Materials Science, 29, 2579-2604 (1994).

DOI: $10.1007 / \mathrm{BF} 00356806$

[37] Keller A., Goldbeck-Wood G., Hikosaka M.: Polymer crystallization: Survey and new trends with wider implications for phase transformations. Faraday Discussions, 95, 109-128 (1993). DOI: $10.1039 /$ FD9939500109

[38] Weynant E., Haudin J. M., G’Sell C.: Plastic deformation and solid-phase transformation in polybutene-1. Journal of Materials Science, 17, 1017-1035 (1982). DOI: $10.1007 / \mathrm{BF} 00543521$
[39] Chau K. W., Yang Y. C., Geil P. H.: Tetragonal $\rightarrow$ twinned hexagonal crystal phase transformation in polybutene-1. Journal of Materials Science, 21, 30023014 (1986).

DOI: $10.1007 / \mathrm{BF} 00553329$

[40] Ninomiya N., Nam P. H., Fujimori T., Masuko T.: Distribution of clay particles in the spherulitic texture of poly(L-lactide)/organo-modified montmorillonite hybrids. e-Polymers, no.041 (2004).

[41] Maiti P., Nam P. H., Okamoto M., Kotaka T., Hasegawa N., Usuki A.: The effect of crystallization on the structure and morphology of polypropylene/ clay nanocomposites. Polymer Engineering and Science, 42, 1864-1871 (2002).

DOI: $10.1002 /$ pen. 11079

[42] Maiti P., Nam P. H., Okamoto M., Hasegawa N., Usuki A.: Influence of crystallization on intercalation, morphology, and mechanical properties of polypropylene/ clay nanocomposites. Macromolecules, 35, 2042-2049 (2002).

DOI: $10.1021 / \mathrm{ma} 010852 \mathrm{z}$

[43] Schaefer D. W., Justice R. S.: How nano are nanocomposites? Macromolecules, 40, 8501-8517 (2007). DOI: $10.1021 / \mathrm{ma} 070356 \mathrm{w}$

[44] Wanjale S. D., Jog J. P.: Crystallization and phase transformation kinetics of poly(1-butene)/MWCNT nanocomposites. Polymer, 47, 6414-6421 (2006). DOI: 10.1016/j.polymer.2006.07.011

[45] Yang B. X., Shi J. H., Li X., Pramoda K.P., Goh S.H.: Mechanical reinforcement of poly(1-butene) using polypropylene-grafted multiwalled carbon nanotubes. Journal of Applied Polymer Science, 113, 1165-1172 (2009).

DOI: $10.1002 / a p p .30056$

[46] Chen W., Feng L., Qu B. J.: Preparation of nanocomposites by exfoliation of ZnAl layered double hydroxides in nonpolar LLDPE solution. Chemistry of Materials, 16, 368-370 (2004).

DOI: $10.1021 / \mathrm{cm} 0303484$

[47] Qiu L., Chen W., Qu B.: Structural characterisation and thermal properties of exfoliated polystyrene/ZnAl layered double hydroxide nanocomposites prepared via solution intercalation. Polymer Degradation and Stability, 87, 433-440 (2005).

DOI: $10.1016 /$ j.polymdegradstab.2004.09.009

[48] Costa F. R., Abdel-Goad M., Wagenknecht U., Heinrich G.: Nanocomposites based on polyethylene and $\mathrm{Mg}-\mathrm{Al}$ layered double hydroxide. I. Synthesis and characterization. Polymer, 46, 4447-4453 (2005). DOI: $10.1016 /$ j.polymer.2005.02.027

[49] Gohil R. M., Miles M. J., Petermann J.: On the molecular mechanism of the crystal transformation (tetragonal-hexagonal) in polybutene-1. Journal of Macromolecular Science Part B: Physics, 21, 189-201 (1982). DOI: $10.1080 / 00222348208204934$ 